\title{
The role of childhood trauma in bipolar disorders
}

\author{
Monica Aas ${ }^{1,2,8^{*}}$, Chantal Henry $3,4,5,6,8$, Ole A. Andreassen ${ }^{1,2,8}$, Frank Bellivier ${ }^{7,6,8}$, Ingrid Melle $1,2,8$ \\ and Bruno Etain ${ }^{3,5,6,8}$
}

\begin{abstract}
This review will discuss the role of childhood trauma in bipolar disorders. Relevant studies were identified via Medline (PubMed) and PsycINFO databases published up to and including July 2015. This review contributes to a new understanding of the negative consequences of early life stress, as well as setting childhood trauma in a biological context of susceptibility and discussing novel long-term pathophysiological consequences in bipolar disorders. Childhood traumatic events are risk factors for developing bipolar disorders, in addition to a more severe clinical presentation over time (primarily an earlier age at onset and an increased risk of suicide attempt and substance misuse). Childhood trauma leads to alterations of affect regulation, impulse control, and cognitive functioning that might decrease the ability to cope with later stressors. Childhood trauma interacts with several genes belonging to several different biological pathways [Hypothalamic-pituitary-adrenal (HPA) axis, serotonergic transmission, neuroplasticity, immunity, calcium signaling, and circadian rhythms] to decrease the age at the onset of the disorder or increase the risk of suicide. Epigenetic factors may also be involved in the neurobiological consequences of childhood trauma in bipolar disorder. Biological sequelae such as chronic inflammation, sleep disturbance, or telomere shortening are potential mediators of the negative effects of childhood trauma in bipolar disorders, in particular with regard to physical health. The main clinical implication is to systematically assess childhood trauma in patients with bipolar disorders, or at least in those with a severe or instable course. The challenge for the next years will be to fill the gap between clinical and fundamental research and routine practice, since recommendations for managing this specific population are lacking. In particular, little is known on which psychotherapies should be provided or which targets therapists should focus on, as well as how childhood trauma could explain the resistance to mood stabilizers.
\end{abstract}

\section{Childhood trauma as a risk factor for psychiatric disorders across diagnostic boundaries}

The WHO (World Health Organization) estimates that a quarter of all adults report having been physically abused as a child, with childhood sexual abuse reported by one in five women and one in 13 men (WHO Library Cataloguing-in-Publication Data 2006). In individuals suffering from severe mental disorders, childhood trauma is reported at a much higher rate. For example, a study from the National Epidemiologic Survey on Alcohol and

\footnotetext{
*Correspondence: monica.aas@medisin.uio.no

1 NORMENT, KG Jebsen Centre for Psychosis Research, TOP Study Group,

Division of Mental Health and Addiction, Institute of Clinical Medicine,

University of Oslo, Bygg 49, Ullevål Sykehus, Nydalen, PO Box 4956,

0424 Oslo, Norway

Full list of author information is available at the end of the article
}

Related Conditions (NESARC) has investigated the risk for any DSM-IV psychiatric disorders when exposed to childhood physical abuse. Such an exposure is associated with increased risks for any substance use disorders $(\mathrm{OR}=1.24[1.07,1.44])$, psychotic disorders $(\mathrm{OR}=1.27$ $[1.00,1.61])$, any mood disorders ( $\mathrm{OR}=1.41[1.25,1.60])$, any anxiety disorders $(\mathrm{OR}=1.56[1.38,1.77])$, and any suicide attempts $(\mathrm{OR}=1.57[1.26,1.96])$ (Sugaya et al. 2012).

Three previous reviews of the literature concerning childhood trauma in BD have been published within a short period of time (Etain et al. 2008; Fisher and Hosang 2010; Daruy-Filho et al. 2011), all showing associations between childhood trauma and BD susceptibility and/ or severity. Since a significant number of studies have been published since 2011 in this domain, an update of

\section{望 Springer}

(c) 2016 Aas et al. This article is distributed under the terms of the Creative Commons Attribution 4.0 International License (http:// creativecommons.org/licenses/by/4.0/), which permits unrestricted use, distribution, and reproduction in any medium, provided you give appropriate credit to the original author(s) and the source, provide a link to the Creative Commons license, and indicate if changes were made. 
these reviews is particularly timely. Furthermore, issues regarding trauma as a whole, as compared with trauma subtypes (emotional, physical and sexual trauma) or gender, have emerged and will be discussed in this review. A considerable amount of literature has also been added to investigate the psychological (dimensions of psychopathology) and biological pathways (in particular, gene/ environment interaction studies) leading from childhood trauma to BD susceptibility and severity. Lastly, we will illustrate that, despite the growing volume of literature in this field, gaps between clinical and biological research and therapeutic implications are still wide.

\section{Childhood trauma as a risk factor in BD}

In 2010, Fisher identified only six robust studies exploring childhood trauma in BD suggesting an association with childhood trauma. Since then, further studies have consolidated the level of proof (Alvarez et al. 2011; Etain et al. 2010; Janiri et al. 2015; Watson et al. 2013). For example, a case-control study assessing 206 patients with BD compared to 94 controls using the Childhood Trauma Questionnaire (CTQ) (Bernstein et al. 1994) shows that multiple traumas are more frequent in patients with $\mathrm{BD}$ than in controls (63 versus $33 \%$ ). Additionally, among trauma subtypes (emotional, physical, and sexual abuses), only emotional abuse has a suggestive dose-effect with BD (Alvarez et al. 2011; Etain et al. 2010). Replication of these results using a smaller sample of 60 patients with $\mathrm{BD}$ versus 55 controls, assessed with the $\mathrm{CTQ}$, shows an association between the BD and CTQ total score. All subscale scores are significantly higher in patients with BD compared to controls, apart from sexual abuse (Watson et al. 2013). Janiri et al. (2015) demonstrate that BD type I patients differ significantly from healthy controls for sexual abuse, and BD type II patients differ from healthy controls for emotional neglect. Maniglio (2013) also reviews 20 studies, including 3407 young and adult patients with BD across 10 countries and three continents, concluding that, compared to healthy individuals, patients with $\mathrm{BD}$ report higher rates of child sexual abuse.

Therefore, childhood trauma in all its subcomponents appears to be highly associated with $\mathrm{BD}$, although the specific role of each trauma subtype (emotional, physical or sexual abuse) remains a subject of debate.

\section{Childhood trauma and severity of the clinical expression of BD}

There are consistent indications that childhood traumatic events are associated with various severe clinical characteristics of $\mathrm{BD}$, including an earlier onset of the illness (Garno et al. 2005), a rapid cycling course (Garno et al. 2005), psychotic features (Bebbington et al. 2004;
Hammersley et al. 2003; Janssen et al. 2004; Shevlin et al. 2007), a higher number of lifetime mood episodes (Brown et al. 2005; Nemeroff, 2004; Weber et al. 2008), and suicide ideation and attempts (Alvarez et al. 2011). However, the quality of these studies has been reported to vary (Daruy-Filho et al. 2011), thus reducing the potential relevance of the findings. Indeed, in a review of 18 studies performed by Daruy-Filho and colleagues (2011), several limitations have been highlighted, including a lack of use of a structured clinical interview for diagnosis, a lack of use of a standardized trauma assessment, a low sample size (less than 100 patients) and insufficient measures of current mood state as a potential confound in trauma assessment (Daruy-Filho et al. 2011). These potential biases are taken into account by a recent large study of patients with $\mathrm{BD}(n=587)$, thereby confirming childhood trauma as being associated with more severe clinical features in BD, including an earlier age of onset, an increased risk of at least one lifetime suicide attempt, rapid cycling, an increased number of mood episodes and substance misuse (Etain et al. 2013a).

Three results appear consistently replicated across studies in BD: (1) the association between childhood trauma and an earlier age at onset; (2) the increased risk for suicide attempts; and (3) comorbid substance misuse. Daruy-Filho et al. (2011) underscored this fact, and since then further replications regarding these three clinical characteristics have been published.

We have demonstrated a dose effect of trauma exposure on the age at onset of BD (Etain et al. 2013a). A recent study of 132 patients with BD from China reports associations between emotional abuse and neglect and an earlier age at onset (Li et al. 2014). Post et al. (2015) also replicate these findings, showing differences in age at onset according to the absence/presence of verbal, physi$\mathrm{cal}$, and sexual abuses. Therefore, exposure to early life stress seems to consistently lower the threshold for developing BD.

Other replicated findings have been obtained for associations between childhood trauma, suicide attempts, and substance misuse in BD, following initial findings reviewed by Daruy-Filho et al. (2011). In a FrenchNorwegian sample of patients with $\mathrm{BD}$, both emotional and sexual abuse are independent predictors of suicide attempts $(\mathrm{OR}=1.60$ [95 \% CI 1.07-2.39] and $\mathrm{OR}=1.80$ [95 \% CI 1.14-2.86], respectively) (Etain et al. 2013a). A recent review by Maniglio (2013) similarly highlights the influence of childhood sexual abuse on the course and severity of $\mathrm{BD}$, including associations with suicide attempts, alcohol andor drug abuse or dependence. The association between childhood trauma and suicide attempt or substance misuse is probably not specific to $\mathrm{BD}$. Indeed, a 25-year-long prospective study examining 
the development of illicit drug use from a birth cohort of 1265 New Zealand children finds that childhood sexual and physical abuse are the main predictors for illicit drug use at age 16-25 (Fergusson et al. 2008). This is consistent with the findings obtained by the NESARC, with associations between physical abuse and an increased risk for any substance use disorders (Sugaya et al. 2012). Moreover, a meta-analysis of longitudinal studies shows an association between sexual abuse and suicide attempt with an OR $=2.43[1.94,3.05]$ (Devries et al. 2014). We can therefore assume that childhood trauma elevates the risk of suicide attempt and substance misuse in BD, this probably being independent of psychiatric diagnoses.

\section{Gender issues and trauma subtypes}

Several studies show that females with BD report childhood trauma more frequently than males (Etain et al. 2013a; Fisher et al. 2009), with one small study showing trend levels in the same direction (Alvarez et al. 2011). For instance, Etain and colleagues (Etain et al. 2013a) indicate higher level of childhood trauma in females compared to males (CTQ total score females $43.5 \pm 14.8$; males $40.1 \pm 12.5 P=0.025)$. In healthy populations, childhood trauma is also more frequently reported by females than males, specifically for sexual abuse, while physical abuse is more frequently reported by healthy males (Fisher et al. 2009). Additionally, greater associations between trauma and clinical characteristics in BD are reported in females. This includes stronger associations to rapid cycling, early onset of illness, increased risk for at least one suicide attempt and more depressive episodes than in males with childhood trauma. Thus, the female gender may drive the association between childhood trauma and the clinical features of BD. This in fact is investigated in the study by Etain et al. (2013a), who find that when gender is added as a covariate in the analysis the results between childhood trauma and the clinical features of BD remain significant, thereby indicating an additive effect of gender, as well as a gender non-specific effect of childhood trauma on clinical characteristics in BD (Etain et al. 2013a).
Another important issue concerns the subtypes of childhood trauma (as compared to trauma in general) that drive these effects on clinical characteristics. Until recently, childhood physical and sexual abuses have been indicated as the strongest predictors of unfavorable clinical characteristics in BD. However, physical and sexual abuse are also the most frequently studied subtypes of childhood trauma, and only a few studies have paid any attention to emotional abuse or neglect (Daruy-Filho et al. 2011). Studies over the past few years may indicate evidence of emotional abuse as a more specific risk factor in BD (Etain et al. 2008, 2010) than other trauma subtypes. Such studies have found a higher prevalence of emotional abuse in patients with BD compared to healthy controls, even after controlling for other types of abuse. A study by Martins et al. (2014) confirms emotional abuse as a risk factor for mood disorders, including patients with BD. Moreover, patients with a history of emotional abuse have higher severity scores on all symptoms, including depression, hopelessness, suicidal ideation, anxiety, and impulsivity. These data may suggest emotional abuse as a specific risk factor for certain psychiatric disorders (possibly with anxious, depressive, and emotional core features). It should also be mentioned here that it is a challenge to separate into different subtypes of trauma, since they often occur together (for an overview of commonly investigated subtypes of childhood trauma, assessed by the CTQ please see Table 1). Future studies should clarify the specific role of each trauma subtype.

\section{Childhood trauma, psychological dimensions, cognition, and brain imaging abnormalities in BD}

One might postulate that childhood trauma is driving clinical outcomes (psychiatric diagnoses or certain clinical features such as suicide attempts) through nonspecific dimensions of psychopathology (e.g., affect or impulse dysregulation or abnormalities in cognitive functioning).

Affective lability is suggested as a core feature of BD (Aminoff et al. 2012; Goodman et al. 2003; Henry et al. 2008) that manifests itself as frequent and intense

Table 1 Trauma subtypes assessed by the CTQ (Bernstein et al. 1994)

\begin{tabular}{ll}
\hline Trauma subtype & Definition \\
\hline Emotional neglect & $\begin{array}{l}\text { Failure of caretakers to meet children's basic emotional and psychological needs, including love, belonging, nurturance, and sup- } \\
\text { port }\end{array}$ \\
$\begin{array}{ll}\text { Emotional abuse } \\
\text { adult or older person }\end{array}$ & $\begin{array}{l}\text { Failure of caretakers to provide for a child's basic physical needs, including food, shelter, clothing, safety, and health care } \\
\text { Physical neglect }\end{array}$ \\
$\begin{array}{l}\text { Physical abuse } \\
\text { Bexual abuse }\end{array}$ & \begin{tabular}{l} 
Sexual contact or conduct between a child younger than 18 years of age and an adult or older person \\
\hline
\end{tabular}
\end{tabular}


fluctuations in affect in response to both pleasant and unpleasant events. In BD, studies have found heightened affective lability in both manic and mixed episodes (Henry et al. 2003), as well as traits during euthymic periods (Henry et al. 2008). A previous study has linked childhood trauma (specifically emotional abuse) to later affective lability in personality disorders and in BD (Goodman et al. 2003). Also in BD, one large study $(n=202)$ and a smaller study $(n=42)$ have demonstrated that exposure to childhood trauma is associated with higher scores on affective lability, with the strongest association being that for emotional abuse (Aas et al. 2014a; Etain et al. 2008). Furthermore, in an Emotion Recognition Task, patients with BD and childhood emotional neglect have a reduced performance in recognizing anger, compared to subjects without any trauma (Russo et al. 2015). Interestingly, childhood trauma is associated with increased amygdala activation (van Harmelen et al. 2013), a brain region important for regulating fear and emotions (Aas et al. 2012; Gallagher and Chiba 1996), thus reinforcing potential links between childhood trauma, changes in emotional or affect regulation and brain imaging abnormalities (limbic system).

Childhood trauma is also a contributing factor to traits of aggression in BD (Garno et al. 2008), suggesting that childhood trauma could influence, in addition to emotional regulation, components of hostility or impulsivity that could prove to increase the risk for suicide attempt or substance misuse (Etain et al. 2013b; Parmentier et al. 2012). This could be related to the effects of childhood trauma on the brain inhibitory control network (Elton et al. 2014), and should be further investigated in BD.

$\mathrm{BD}$ patients also present deficits in cognitive functioning, particularly in areas of working memory, executive functioning, attention, and processing speed (Bourne et al. 2013). The mechanisms behind these impairments are poorly understood, and potentially based on both heritability and environmental susceptibility factors. Very few studies have investigated the potential role of childhood trauma on cognitive impairment in BD. A recent study of early $\mathrm{BD}$ demonstrates that patients with childhood trauma have poorer scores on IQ, attention, verbal memory and working memory (Bucker et al. 2013), with these associations remaining significant after taking into account current mood symptoms. Similar findings have also been reported in a more established stage of $\mathrm{BD}$ (Savitz et al. 2008).

The relationships between childhood trauma, dimensions of psychopathology, and cognition may help shed light on the clinical overlap or comorbidities between $\mathrm{BD}$ and other clinical entities such as those related to affect dysregulation, impulsivity and hostility (borderline personality, suicide behaviors and substance misuse). They could also lead to a greater vulnerability to other environmental stressors such as cannabis exposure or adulthood life events.

\section{Interactions between childhood trauma and later stressors in BD}

A two-hits model of susceptibility has been proposed in psychosis, and could show relevance for BD (Cannon et al. 2014). Briefly, exposure to prenatal or postnatal stressors interacts with genetic factors to "prime" the brain, which leads to a vulnerability as measured by changes in brain functioning or other biomarkers. Further stressors during adolescence or young adulthood (substance misuse, stressful events) may serve to convert the vulnerability into a disorder. In $\mathrm{BD}$, the interaction between childhood trauma and susceptibility genes may predispose the individual to subtle changes in certain biological and physiopathological processes of the disorder. In this context, cannabis misuse during adolescence or later life events may act in and reveal this susceptibility or increasing the rate of mood recurrences.

The additive effects of childhood trauma and cannabis misuse have been demonstrated by increased rates for rapid cycling at an earlier age at onset and suicide attempt (Aas et al. 2014b), thus supporting the hypothesis of a two-hit model of susceptibility in BD. The possible mechanism behind the co-occurrence of childhood abuse and cannabis abuse could be related to their opposite effects on the hypothalamic-pituitary-adrenal (HPA) axis (Heim et al. 2008; van Leeuwen et al. 2011). Cannabis and substance misuse have been linked to a reduction in HPA activity (van Leeuwen et al. 2011), while a history of childhood trauma has been linked to increased HPA axis activity, specifically in depression (Heim et al. 2008). As a result, it could be hypothesized that cannabis or substance use in individuals with a history of childhood trauma serve a purpose of self-medication to "regulate" the HPA axis, alongside the emotional turmoil caused by the childhood trauma events.

Several studies have examined the role of stressful adult life events and episode recurrence in BD (Cohen et al. 2004; Johnson and Roberts 1995; Swendsen et al. 1995). The study by Cohen et al. (2004), consisting of 52 patients with BD type I, finds that high levels of stressful life events in adulthood predict depressive recurrence over a one-year follow-up after controlling for clinical history and compliance. Similarly, Swendsen et al. (1995) conclude that stressful life events in adulthood are predictors of a more severe symptomatology over a one-year period. Research by Johnson and Miller (1997) observes that BD patients with severe negative life events in adulthood require a recovery period threefold longer in duration compared to those without adverse life events, as 
life events increase the risk of both first- and recurrent admissions in BD (Kemner et al. 2015). There is no study that specifically investigates the interaction between childhood trauma and later life events as to the severity of $\mathrm{BD}$, but we can postulate that having a history of childhood trauma increases the risk for an elevated response to later negative/positive life events by increased stress reactivity (Aas et al. 2011; Aas et al. 2014c). This could be mediated by changes in affect regulation, cognitive functioning or an increased impulsivity in association with maladaptive coping mechanisms. BD patients with histories of childhood trauma may be less likely to have protective factor "buffers," including secure attachment and social support, again enhancing a vulnerability to the negative long-term effects of childhood trauma.

\section{Biological systems implicated in the association between childhood trauma and BD}

It is beyond the scope of this article to review all the relevant biological systems that could play a role in mediating the impact of childhood trauma on the risk of developing $\mathrm{BD}$ or a more severe form of the disorder. Some of them (neuroplasticity, inflammation, circadian system or HPA axis) could be much more central in BD.

A first mechanism linking childhood trauma to BD susceptibility relies on neuroplasticity mechanisms, in particular BDNF, which is a neurotrophic imperative for the growth and differentiation of neurons during brain development and the maintenance of neurons in adult life. A reduction of BDNF serum or mRNA levels (Aas et al. 2014c; Kauer-Sant'Anna et al. 2007) has been observed after exposure to traumatic events in BD. Second, independently of psychiatric diagnoses, childhood trauma induces long-term modifications in inflammation processes (Baumeister et al. 2015; Coelho et al. 2014; Tursich et al. 2014). This should be studied in patients with BD who show CRP abnormalities (Dargel et al. 2015), and various cytokines such as Interleukin (IL)-2 receptor, tumor necrosis factor- $\alpha$, soluble tumor necrosis factor receptor type 1, IL-6, and IL-4 (Munkholm et al. 2013). Interestingly, some authors have proposed a potential interaction between an elevated BDNF and pro-inflammatory cytokine levels after trauma (Bucker et al. 2015), with an increase in BDNF levels being a possible attempt to neutralize the negative effects of CT on the brain.

Sleep disturbances observed in BD (Geoffroy et al. 2015; Ng et al. 2015) should also be studied in the context of childhood trauma. Indeed, in the general population, childhood adversity is a risk factor for adult sleep disorders (Baiden et al. 2015; Koskenvuo et al. 2010). Since the circadian system modulates the biological responses to stressful environmental factors (Landgraf et al. 2014), this hypothesis should require more attention. To date, only one study has explored such a hypothesis among patients with anxiety and depressive disorders and found that a high stress load in childhood was associated with alterations in several sleep parameters assessed with actigraphy (Schafer and Bader 2013).

Further research is also required regarding the impact of childhood trauma on the HPA axis functioning in BD. A meta-analysis in schizophrenia and BD shows heightened levels of morning cortisol in BD (Girshkin et al. 2014), although the determinants of such modifications and the specific place of childhood trauma among them require further investigations.

As a potential future perspective, most of these biological systems possibly interact and converge to a high physical burden and reduced life expectancy in patients with BD (Kessing et al. 2015). Indeed, a meta-analysis by Norman et al. (2012) explores the long-term consequences of childhood abuse and neglect, and finds associations not only with psychiatric, but also with physical disorders. Through long-lasting consequences on the alterations of immune-inflammatory markers, sleep parameters and HPA axis, childhood trauma might be associated with poor health conditions and, as such, this hypothesis deserves more attention.

\section{Underlying molecular mechanisms in BD}

Several mechanisms are likely to be involved in mediating the consequences of childhood trauma at the molecular level, with interactions between childhood trauma and genetic variants, epigenetics mechanisms and shortened telomere length being only a few.

\section{Gene-environment interactions in BD}

Exposure to childhood trauma is thought to interact with various susceptibility genes to increase the risk of $\mathrm{BD}$, or to a more severe clinical expression of the expression of the disorder. This mechanism is called "gene-environment interaction," in which the phenotypic response to an environmental factor is conditioned by the genotype of the individuals. Although the literature is scant in BD, interactions between childhood trauma and candidate genes (BNDF, 5HTTLPR, TLR2, calcium-related genes, circadian genes) have been reported to influence age at onset or suicidal risk.

Miller et al. (2013) demonstrate differences in variants of the BDNF val66met and sexual abuse on the age at onset in BD; only Met carriers exposed to childhood sexual abuse have an earlier age at onset. Benedetti et al. (2014) show an interaction between trauma and 5 HTTLPR on suicidality and age at onset in BD. Here, homozygotes for the short variant of the 5HTTLPR and trauma have increased the risk of suicide attempts and an earlier age of onset compared to all other groups. Etain 
et al. (2015) similarly support an interaction between emotional trauma and the 5HTTLPR on the age at the onset of BD (Etain et al. 2015). Oliveira et al. (2015) demonstrate an interaction between sexual abuse and a TLR2 (Toll-Like Receptor 2 belonging to immuneinflammatory pathways) variant on the age at the onset of BD (Oliveira et al. 2015). Here, TT homozygotes who reported sexual abuse had an earlier age at the onset of BD. Anand et al. (2015) demonstrate a relationship between trauma and SNPs in or near genes coding for calcium channel activity-related proteins and an earlier age at the onset of BD. Finally, Benedetti et al. (2015) suggest a combination of specific variants of the CLOCK gene (belonging to the circadian system) in combination with early stress, which may drive the elevated prevalence of suicide attempts in $\mathrm{BD}$. Here, in comparison to other groups, $\mathrm{C}$ carriers in the presence of a delayed sleep onset and worsening insomnia exhibit an increased risk for suicide attempts in the presence of childhood trauma.

These results suggest complex effects of trauma exposure on age at onset or suicidality in BD, moderated by genes that belong to pathways involved in neuroplasticity, inflammation, serotonergic neurotransmission, calcium signaling or circadian rhythms. Interaction between childhood trauma and genes belonging to the HPA axis pathways have already been explored for depression and psychosis, but not yet for BD (Uher 2014).

\section{Epigenetic molecular mechanisms}

One adaptive mechanism to help modulate stress response is to act through subtle modifications of gene expression, primarily through epigenetic mechanisms such as methylation and histone modifications. Both pre(Seckl and Meaney 2004) and perinatal (Fish et al. 2004) stress have long-term effects on the HPA axis (Herbert et al. 2006) in rodent models and humans. The altered HPA axis in adult humans exposed to childhood trauma may be related to epigenetic changes of stress regulatory genes, such as the glucocorticoid receptor (GR) gene, also called the "NR3C1 gene," or the FKBP5 gene (Klengel et al. 2013) (a glucocorticoid receptor co-chaperone). Even if epigenetic modification in response to early environmental conditions could provide a future elegant mechanism to explain the effects of childhood adversity on an increasing risk of psychopathology in adulthood, this remains to be specifically explored in BD (Nemeroff and Binder 2014).

\section{Telomere length}

Telomeres are the DNA-based caps and protein structures at the chromosome tips, which shorten after each cell division, their length being used as a marker of biological aging (Shalev et al. 2013), as well as being associated with diabetes mellitus type II, coronary heart disease and cancer in the general population (Haycock et al. 2014; Ma et al. 2011; Wentzensen et al. 2011; Willeit et al. 2014). A shorter telomere length may be partially related to early stressor events. Indeed, two recent review articles suggest that childhood trauma is a causal factor for the long-term reduction of telomere length (Price et al. 2013; Shalev et al. 2013). Two studies have also shown a reduced telomere length in $\mathrm{BD}$ compared to controls (Elvsashagen et al. 2011; Lima et al. 2014), whereas others found negative results (Colpo et al. 2015). Hence, the association between childhood trauma and telomere length, along with the association with physical health, deserve future attention in BD.

\section{Implications for clinical assessment and treatment}

First, a routine assessment of childhood trauma in both the early phases and established cases of BD should be undertaken due to the heightened risk of developing a more severe illness over time. It has previously been reported that abuse is often inadequately assessed in psychiatric clinics (Read and Fraser 1998), an aspect to be considered in the overall assessment process. The assessment of childhood trauma is particularly required for subgroups of patients with BD with early onset, comorbidity with suicide attempts or substance misuse, high level of mood recurrences or greater mood instability (as a categorical pattern, i.e., rapid cycling or as a dimensional one, i.e., affective lability). In routine practice, an assessment should be undertaken using clinical interviews, which would also benefit from the systematic use of questionnaires. It is beyond the scope of this review to discuss in depth the respective psychometric properties of interviews and self-reports. Since more than 20 self-reports and 20 interviews exist with some difference between psychometric qualities, none of them can be recommended more than another (Roy and Perry 2004). Nevertheless, the use of the CTQ may be relevant, as it is widely used in clinical research in $\mathrm{BD}$, while also exploring different subtypes of trauma and not only physical or sexual abuse.

Second, addressing childhood trauma could be a focus of early intervention strategies and approaches to potentially prevent these individuals from developing an unalterable chronic illness over time; however this is only speculation. As described in Thompson et al. (2014), examples of treatment targets (working directly on the dissociative experiences in response to trauma) could be psychological techniques, coping strategies, body awareness/mindfulness techniques and stress management. Because a history of childhood trauma is also associated with reduced functioning in childhood, reaching these individuals before illness onset could potentially reduce 
the severity and (hypothetically) the development of the illness. Although existing data support several psychological interventions in effectively preventing or treating the negative consequences of childhood trauma in general (eye moment desensitization and reprocessing [EMDR], trauma focused Cognitive behavioral therapy [CBT] for sexually abused children) (Ehring et al. 2014; Macdonald et al. 2012), studies in established cases of BD are sparse. Landin-Romero et al. (2013) and Mueser et al. (2008) assessed a sample of 108 patients with PTSD and either major mood disorder (85\%), schizoaffective disorder or schizophrenia (15\%), of whom $25 \%$ also had a borderline personality disorder using CBT. CBT patients improved significantly more than patients in the treatment as usual group at a blinded post-treatment and the 3- and 6-month follow-up. Due to findings of childhood trauma being associated with affective dysregulation in BD (Aas et al. 2014a) and impulsivity (Etain et al. 2013b), as well as rapid cycling (Etain et al. 2013a), psychosocial therapies should target not only traumatic experiences per se, but also cognitive defects or emotional dysregulation linked to traumatic experiences. In this context, therapies that target emotional regulation or cognitive functioning might help counterbalance the negative effects of trauma. To date, this is under-researched in the field, but deserves some attention. This will also open discussions about how those patients with BD exposed to trauma would respond in a similar manner to "classical" or more targeted psychosocial therapies.

Studies exploring treatment resistance in BD should also integrate childhood trauma as a potential predictor of non-response. Indeed, childhood trauma has been associated with a poorer response in resistant-depression (Douglas and Porter 2012; Shamseddeen et al. 2011), obsessive-compulsive disorder and schizophrenia (Hassan and de Luca 2015; Semiz et al. 2014), but never investigated in BD. Randomized controlled trials of the efficacy of interventions could easily assess childhood trauma at baseline to study how this factor is relevant in selecting those who might or might not respond to treatment. A promising area for investigation could be a nonresponse to lithium, for which robust predictors are still lacking.

\section{Perspectives and research gaps}

Childhood traumatic events are potential risk factors, both for developing $\mathrm{BD}$ and presenting a more severe disorder over time. This association is probably not specific to $\mathrm{BD}$, with childhood trauma predisposing to transnosographic indicators of severity, such as suicide attempts or substance misuse. At a dimensional level, childhood trauma may lead to abnormalities in affect regulation, impulse control and cognitive functioning that could reduce the ability to cope with later environmental risk factors (cannabis misuse, stressful life events). This leads to the absolute recommendation that clinicians should assess childhood trauma, ideally for every patient with $\mathrm{BD}$, but at least for those with a more severe, unstable or relapsing course.

Several biological pathways (including neuroplasticity, inflammation, circadian systems, and HPA axis) are likely to play a role in the long-lasting consequences of childhood trauma on the risk for (severe) BD, in addition to the high level of somatic comorbidities. Preliminary results demonstrate that candidate genes belonging to these pathways help moderate the effects of childhood trauma on age at onset and suicidality in BD. Although promising, this research is still emerging in $\mathrm{BD}$, and further studies are needed to clarify the involved biological pathways. In particular, some results remain to be consolidated such as the impact on brain structures and functioning, or the identification of epigenetic or transcriptomic biomarkers, in those who are at-risk of negative consequences when exposed to trauma (versus those who would be resilient). To date, the literature has primarily focused on psychological or cognitive outcomes after childhood trauma in BD, and much attention is required for the consequences on physical health in patients with BD.

At last, a large gap is present between clinical observation on the role of childhood trauma in $\mathrm{BD}$, and the quasi-absence of treatment guidelines for this population. Psychosocial interventions and their preferential targets are not yet, and the implication of childhood trauma in treatment resistance (psychotherapies or medications) is totally absent in the literature. Clinicians and researchers should therefore gather to foster this reflection that would contribute to more personalized care plans for those exposed to trauma. Given the importance of trauma in prognosis and course in patients with $\mathrm{BD}$, we should not only content ourselves with simply extrapolating the PTSD literature in terms of management, but should also provide evidence-based trauma interventions in $\mathrm{BD}$.

\section{Authors' contributions}

All authors have contributed to and have approved the final manuscript. MA and $\mathrm{BE}$ wrote the initial draft. $\mathrm{CH}, \mathrm{OAA}, \mathrm{FB}$, and IM contributed to bibliographic searches and drafting of the final manuscript.

\section{Author details}

${ }^{1}$ NORMENT, KG Jebsen Centre for Psychosis Research, TOP Study Group, Division of Mental Health and Addiction, Institute of Clinical Medicine, University of Oslo, Bygg 49, Ullevål Sykehus, Nydalen, PO Box 4956, 0424 Oslo, Norway. ${ }^{2}$ Division of Mental Health and Addiction, Oslo University Hospital, Oslo, Norway. ${ }^{3}$ AP-HP, Hôpitaux Universitaires Henri Mondor, DHU Pepsy, Pôle de Psychiatrie, 94000 Créteil, France. ${ }^{4}$ Université Paris Est, Faculté de Médecine, 94000 Créteil, France. ${ }^{5}$ Inserm, U955, 94000 Créteil, France. ${ }^{6}$ Fondation Fondamental, Créteil, France. ${ }^{7}$ AP-HP, Hôpital Fernand Widal, Pôle Addictologie-Toxicologie-Psychiatrie and Université Paris-7, Paris, France. ${ }^{8}$ ENBREC, European Network of Bipolar Research Expert Centres (ENBREC), Paris, France. 


\section{Acknowledgements}

This research was funded by INSERM, AP-HP, ANR, and FRC in France. This study was also funded by a grant from the University of Oslo, the South-Eastern Norway Health Authority (\#2013088), the Research Council of Norway, the KG Jebsen Foundation, the SCNP Young Scientist Award and a NARSAD Young Investigator Grant (ID: 22388) to Monica Aas. These organizations had no role in the design of the study, the writing of the report, or the decision to submit the paper for publication.

\section{Competing interests}

The authors declare that they have no competing interests.

Received: 25 September 2015 Accepted: 13 December 2015 Published online: 13 January 2016

\section{References}

Aas M, Dazzan P, Fisher HL, Morgan C, Morgan K, Reichenberg A, Zanelli J, Fearon P, Jones PB, Murray RM, Pariante CM. Childhood trauma and cognitive function in first-episode affective and non-affective psychosis. Schizophr Res. 2011;129:12-9.

Aas M, Navari S, Gibbs A, Mondelli V, Fisher HL, Morgan C, Morgan K, Maccabe J, Reichenberg A, Zanelli J, Fearon P, Jones PB, Murray RM, Pariante CM, Dazzan P. Is there a link between childhood trauma, cognition, and amygdala and hippocampus volume in first-episode psychosis? Schizophr Res. 2012;137:73-9.

Aas M, Aminoff SR, Vik LT, Etain B, Agartz I, Andreassen OA, Melle I. Affective lability in patients with bipolar disorders is associated with high levels of childhood trauma. Psychiatry Res. 2014a;218:252-5.

Aas M, Etain B, Bellivier F, Henry C, Lagerberg T, Ringen A, Agartz I, Gard S, Kahn JP, Leboyer M, Andreassen OA, Melle I. Additive effects of childhood abuse and cannabis abuse on clinical expressions of bipolar disorders. Psychol Med. 2014b;44:1653.

Aas M, Haukvik UK, Djurovic S, Tesli M, Athanasiu L, Bjella T, Hansson L, Cattaneo A, Agartz I, Andreassen OA, Melle I. Interplay between childhood trauma and BDNF val66met variants on blood BDNF mRNA levels and on hippocampus subfields volumes in schizophrenia spectrum and bipolar disorders. J Psychiatr Res. 2014c;59:14.

Alvarez MJ, Roura P, Oses A, Foguet Q, Sola J, Arrufat FX. Prevalence and clinical impact of childhood trauma in patients with severe mental disorders. J Nerv Ment Dis. 2011;199:156-61.

Aminoff SR, Jensen J, Lagerberg TV, Hellvin T, Sundet K, Andreassen OA, Melle I. An association between affective lability and executive functioning in bipolar disorder. Psychiatry Res. 2012;198:58-61.

Anand A, Koller DL, Lawson WB, Gershon ES, Nurnberger Jl. Genetic and childhood trauma interaction effect on age of onset in bipolar disorder: an exploratory analysis. J Affect Disord. 2015;179:1-5.

Baiden P, Fallon B, den Dunnen W, Boateng G. The enduring effects of earlychildhood adversities and troubled sleep among Canadian adults: a population-based study. Sleep Med. 2015;16:760-7.

Baumeister D, Akhtar R, Ciufolini S, Pariante CM, Mondelli V. Childhood trauma and adulthood inflammation: a meta-analysis of peripheral C-reactive protein, interleukin-6 and tumour necrosis factor-a. Mol Psychiatry. 2015.

Bebbington PE, Bhugra D, Brugha T, Singleton N, Farrell M, Jenkins R, Lewis G, Meltzer H. Psychosis, victimisation and childhood disadvantage: evidence from the second British National Survey of Psychiatric Morbidity. Br J Psychiatry. 2004;185:220-6.

Benedetti F, Riccaboni R, Dallaspezia S, Locatelli C, Smeraldi E, Colombo C. Effects of CLOCK gene variants and early stress on hopelessness and suicide in bipolar depression. Chronobiol Int. 2015;32:1156.

Benedetti F, Riccaboni R, Poletti S, Radaelli D, Locatelli C, Lorenzi C, Pirovano A, Smeraldi E, Colombo C. The serotonin transporter genotype modulates the relationship between early stress and adult suicidality in bipolar disorder. Bipolar Disord. 2014;16:857-66.

Bernstein DP, Fink L, Handelsman L, Foote J, Lovejoy M, Wenzel K, Sapareto E, Ruggiero J. Initial reliability and validity of a new retrospective measure of child abuse and neglect. Am J Psychiatry. 1994;151:1132-6.

Bourne C, Aydemir O, Balanza-Martinez V, Bora E, Brissos S, Cavanagh JT, Clark L, Cubukcuoglu Z, Dias W, Dittmann S, Ferrier IN, Fleck DE, Frangou
S, Gallagher P, Jones L, Kieseppa T, Martinez-Aran A, Melle I, Moore PB, Mur M, Pfennig A, Raust A, Senturk V, Simonsen C, Smith DJ, Bio DS, Soeiro-de-Souza MG, Stoddart SD, Sundet K, Szoke A, Thompson JM, Torrent C, Zalla T, Craddock N, Andreassen OA, Leboyer M, Vieta E, Bauer M, Worhunsky PD, Tzagarakis C, Rogers RD, Geddes JR, Goodwin GM. Neuropsychological testing of cognitive impairment in euthymic bipolar disorder: an individual patient data meta-analysis. Acta Psychiatr Scand. 2013;128:149-62.

Brown GR, McBride L, Bauer MS, Williford WO. Impact of childhood abuse on the course of bipolar disorder: a replication study in U.S. veterans. J Affect Disord. 2005;89:57-67.

Bucker J, Fries GR, Kapczinski F, Post RM, Yatham LN, Vianna P, Bogo Chies JA, Gama CS, Magalhaes PV, Aguiar BW, Pfaffenseller B, Kauer-Sant'Anna M. Brain-derived neurotrophic factor and inflammatory markers in schoolaged children with early trauma. Acta Psychiatr Scand. 2015;131:360-8.

Bucker J, Kozicky J, Torres IJ, Kauer-Sant'Anna M, Silveira LE, Bond DJ, Lam RW, Yatham LN. The impact of childhood trauma on cognitive functioning in patients recently recovered from a first manic episode: data from the Systematic Treatment Optimization Program for Early Mania (STOP-EM). J Affect Disord. 2013;148:424-30.

Cannon M, Clarke MC, Cotter DR. Priming the brain for psychosis: maternal inflammation during fetal development and the risk of later psychiatric disorder. Am J Psychiatry. 2014;171:901-5.

Coelho R, Viola TW, Walss-Bass C, Brietzke E, Grassi-Oliveira R. Childhood maltreatment and inflammatory markers: a systematic review. Acta Psychiatr Scand. 2014;129:180-92.

Cohen AN, Hammen C, Henry RM, Daley SE. Effects of stress and social support on recurrence in bipolar disorder. J Affect Disord. 2004;82:143-7.

Colpo GD, Leffa DD, Kohler CA, Kapczinski F, Quevedo J, Carvalho AF. Is bipolar disorder associated with accelerating aging? A meta-analysis of telomere length studies. J Affect Disord. 2015;186:241-8.

Dargel AA, Godin O, Kapczinski F, Kupfer DJ, Leboyer M. C-reactive protein alterations in bipolar disorder: a meta-analysis. J Clin Psychiatry. 2015;76:142-50

Daruy-Filho L, Brietzke E, Lafer B, Grassi-Oliveira R. Childhood maltreatment and clinical outcomes of bipolar disorder. Acta Psychiatr Scand. 2011;124:427-34.

Devries KM, Mak JY, Child JC, Falder G, Bacchus LJ, Astbury J, Watts CH. Childhood sexual abuse and suicidal behavior: a meta-analysis. Pediatrics. 2014;133:e1331-44.

Douglas KM, Porter RJ. The effect of childhood trauma on pharmacological treatment response in depressed inpatients. Psychiatry Res. 2012;200:1058-61.

Ehring T, Welboren R, Morina N, Wicherts JM, Freitag J, Emmelkamp PM. Metaanalysis of psychological treatments for posttraumatic stress disorder in adult survivors of childhood abuse. Clin Psychol Rev. 2014;34:645-57.

Elton A, Tripathi SP, Mletzko T, Young J, Cisler JM, James GA, Kilts CD. Childhood maltreatment is associated with a sex-dependent functional reorganization of a brain inhibitory control network. Hum Brain Mapp. 2014;35:1654-67.

Elvsashagen T, Vera E, Boen E, Bratlie J, Andreassen OA, Josefsen D, Malt UF, Blasco MA, Boye B. The load of short telomeres is increased and associated with lifetime number of depressive episodes in bipolar II disorder. J Affect Disord. 2011;135:43-50.

Etain B, Henry C, Bellivier F, Mathieu F, Leboyer M. Beyond genetics: childhood affective trauma in bipolar disorder. Bipolar Disord. 2008;10:867-76.

Etain B, Mathieu F, Henry C, Raust A, Roy I, Germain A, Leboyer M, Bellivier F. Preferential association between childhood emotional abuse and bipolar disorder. J Trauma Stress. 2010;23:376-83.

Etain B, Aas M, Andreassen OA, Lorentzen S, Dieset I, Gard S, Kahn JP, Bellivier F, Leboyer M, Melle I, Henry C. Childhood trauma is associated with severe clinical characteristics of bipolar disorders. J Clin Psychiatry. 2013a;74:991-8.

Etain B, Mathieu F, Liquet S, Raust A, Cochet B, Richard JR, Gard S, Zanouy L, Kahn JP, Cohen RF, Bougerol T, Henry C, Leboyer M, Bellivier F. Clinical features associated with trait-impulsiveness in euthymic bipolar disorder patients. J Affect Disord. 2013b;144:240-7.

Etain B, Lajnef M, Henrion A, Dargél AA, Stertz L, Kapczinski F, Mathieu F, Henry C, Gard S, Kahn JP, Leboyer M, Jamain S, Bellivier F. Interaction between SLC6A4 promoter variants and childhood trauma on the age at onset of bipolar disorders. Sci Rep. 2015;5:16301. 
Fergusson DM, Boden JM, Horwood LJ. The developmental antecedents of illicit drug use: evidence from a 25-year longitudinal study. Drug Alcohol Depend. 2008;96:165-77.

Fish EW, Shahrokh D, Bagot R, Caldji C, Bredy T, Szyf M, Meaney MJ. Epigenetic programming of stress responses through variations in maternal care. Ann N Y Acad Sci. 2004;1036:167-80.

Fisher H, Morgan C, Dazzan P, Craig TK, Morgan K, Hutchinson G, Jones PB, Doody GA, Pariante C, McGuffin P, Murray RM, Leff J, Fearon P. Gender differences in the association between childhood abuse and psychosis. Br J Psychiatry. 2009;194:319-25.

Fisher HL, Hosang GM. Childhood maltreatment and bipolar disorder: a critical review of the evidence. Mind Brain. 2010;1(1):75-85.

Gallagher M, Chiba AA. The amygdala and emotion. Curr Opin Neurobiol. 1996;6:221-7.

Garno JL, Goldberg JF, Ramirez PM, Ritzler BA. Impact of childhood abuse on the clinical course of bipolar disorder. Br J Psychiatry. 2005;186:121-5.

Garno JL, Gunawardane N, Goldberg JF. Predictors of trait aggression in bipolar disorder. Bipolar Disord. 2008;10:285-92.

Geoffroy PA, Scott J, Boudebesse C, Lajnef M, Henry C, Leboyer M, Bellivier F, Etain B. Sleep in patients with remitted bipolar disorders: a meta-analysis of actigraphy studies. Acta Psychiatr Scand. 2015;131:89-99.

Girshkin L, Matheson SL, Shepherd AM, Green MJ. Morning cortisol levels in schizophrenia and bipolar disorder: a meta-analysis. Psychoneuroendocrinology. 2014;49:187-206.

Goodman M, Weiss DS, Koenigsberg H, Kotlyarevsky V, New AS, Mitropoulou $\checkmark$, Silverman JM, O'Flynn K, Siever LJ. The role of childhood trauma in differences in affective instability in those with personality disorders. CNS Spectr. 2003;8:763-70.

Hammersley P, Dias A, Todd G, Bowen-Jones K, Reilly B, Bentall RP. Childhood trauma and hallucinations in bipolar affective disorder: preliminary investigation. Br J Psychiatry. 2003;182:543-7.

Hassan AN, de Luca V. The effect of lifetime adversities on resistance to antipsychotic treatment in schizophrenia patients. Schizophr Res. 2015;161:496-500.

Haycock PC, Heydon EE, Kaptoge S, Butterworth AS, Thompson A, Willeit P. Leucocyte telomere length and risk of cardiovascular disease: systematic review and meta-analysis. BMJ. 2014;349:94227.

Heim C, Newport DJ, Mletzko T, Miller AH, Nemeroff CB. The link between childhood trauma and depression: insights from HPA axis studies in humans. Psychoneuroendocrinology. 2008;33:693-710.

Henry C, Swendsen J, Van den Bulke D, Sorbara F, Demotes-Mainard J, Leboyer M. Emotional hyper-reactivity as a fundamental mood characteristic of manic and mixed states. Eur Psychiatry. 2003;18:124-8.

Henry C, Van den Bulke D, Bellivier F, Roy I, Swendsen J, M'Bailara K, Siever LJ, Leboyer M. Affective lability and affect intensity as core dimensions of bipolar disorders during euthymic period. Psychiatry Res. 2008;159:1-6

Herbert J, Goodyer IM, Grossman AB, Hastings MH, de Kloet ER, Lightman SL, Lupien SJ, Roozendaal B, Seckl JR. Do corticosteroids damage the brain? J Neuroendocrinol. 2006;18:393-411.

Janiri D, Sani G, Danese E, Simonetti A, Ambrosi E, Angeletti G, Erbuto D, Caltagirone C, Girardi P, Spalletta G. Childhood traumatic experiences of patients with bipolar disorder type I and type II. J Affect Disord. 2015;175:92-7.

Janssen I, Krabbendam L, Bak M, Hanssen M, Vollebergh W, de Graaf R, van Os J. Childhood abuse as a risk factor for psychotic experiences. Acta Psychiatr Scand. 2004;109:38-45.

Johnson SL, Miller I. Negative life events and time to recovery from episodes of bipolar disorder. J Abnorm Psychol. 1997;106:449-57.

Johnson SL, Roberts JE. Life events and bipolar disorder: implications from biological theories. Psychol Bull. 1995;117:434-49.

Kauer-Sant'Anna M, Tramontina J, Andreazza AC, Cereser K, da Costa S, Santin A, Yatham LN, Kapczinski F. Traumatic life events in bipolar disorder: impact on BDNF levels and psychopathology. Bipolar Disord. 2007;9(Suppl 1):128-35.

Kemner SM, van Haren NE, Bootsman F, Eijkemans MJ, Vonk R, van der Schot AC, Nolen WA, Hillegers MH. The influence of life events on first and recurrent admissions in bipolar disorder. Int J Bipolar Disord. 2015;3:6.

Kessing LV, Vradi E, McIntyre RS, Andersen PK. Causes of decreased life expectancy over the life span in bipolar disorder. J Affect Disord. 2015:180:142-7.
Klengel T, Mehta D, Anacker C, Rex-Haffner M, Pruessner JC, Pariante CM, Pace TW, Mercer KB, Mayberg HS, Bradley B, Nemeroff CB, Holsboer F, Heim CM, Ressler KJ, Rein T, Binder EB. Allele-specific FKBP5 DNA demethylation mediates gene-childhood trauma interactions. Nat Neurosci. 2013;16:33-41.

Koskenvuo K, Hublin C, Partinen M, Paunio T, Koskenvuo M. Childhood adversities and quality of sleep in adulthood: a population-based study of 26,000 Finns. Sleep Med. 2010;11:17-22.

Landgraf D, McCarthy MJ, Welsh DK. Circadian clock and stress interactions in the molecular biology of psychiatric disorders. Curr Psychiatry Rep. 2014; 16:483.

Landin-Romero R, Novo P, Vicens V, McKenna PJ, Santed A, Pomarol-Clotet E, Salgado-Pineda P, Shapiro F, Amann BL. EMDR therapy modulates the default mode network in a subsyndromal, traumatized bipolar patient. Neuropsychobiology. 2013;67:181-4.

Li XB, Liu JT, Zhu XZ, Zhang L, Tang YL, Wang CY. Childhood trauma associates with clinical features of bipolar disorder in a sample of Chinese patients. J Affect Disord. 2014;168:58-63.

Lima IM, Barros A, Rosa DV, Albuquerque M, Malloy-Diniz L, Neves FS, RomanoSilva MA, de Miranda DM. Analysis of telomere attrition in bipolar disorder. J Affect Disord. 2014;172C:43-7.

Ma H, Zhou Z, Wei S, Liu Z, Pooley KA, Dunning AM, Svenson U, Roos G, Hosgood HD III, Shen M, Wei Q. Shortened telomere length is associated with increased risk of cancer: a meta-analysis. PLoS One. 2011;6:e20466.

Macdonald G, Higgins JP, Ramchandani P, Valentine JC, Bronger LP, Klein P, O'Daniel R, Pickering M, Rademaker B, Richardson G, Taylor M. Cognitive-behavioural interventions for children who have been sexually abused. Cochrane Database Syst Rev. 2012;5:CD001930.

Maniglio R. Prevalence of child sexual abuse among adults and youths with bipolar disorder: a systematic review. Clin Psychol Rev. 2013;33:561-73.

Martins CM, Von Werne BC, Tofoli SM, Juruena MF. Emotional abuse in childhood is a differential factor for the development of depression in adults. J Nerv Ment Dis. 2014;202:774-82.

Miller S, Hallmayer J, Wang PW, Hill SJ, Johnson SL, Ketter TA. Brain-derived neurotrophic factor val66met genotype and early life stress effects upon bipolar course. J Psychiatr Res. 2013;47:252-8.

Mueser KT, Rosenberg SD, Xie H, Jankowski MK, Bolton EE, Lu W, Hamblen $J$, Rosenberg HJ, McHugo GJ, Wolfe R. A randomized controlled trial of cognitive-behavioral treatment for posttraumatic stress disorder in severe mental illness. J Consult Clin Psychol. 2008;76:259-71.

Munkholm K, Brauner JV, Kessing LV, Vinberg M. Cytokines in bipolar disorder vs. healthy control subjects: a systematic review and meta-analysis. J Psychiatr Res. 2013;47:1119-33.

Nemeroff CB. Neurobiological consequences of childhood trauma. J Clin Psychiatry. 2004;65(Suppl 1):18-28.

Nemeroff CB, Binder E. The preeminent role of childhood abuse and neglect in vulnerability to major psychiatric disorders: toward elucidating the underlying neurobiological mechanisms. J Am Acad Child Adolesc Psychiatry. 2014;53:395-7.

Ng TH, Chung KF, Ho FY, Yeung WF, Yung KP, Lam TH. Sleep-wake disturbance in interepisode bipolar disorder and high-risk individuals: a systematic review and meta-analysis. Sleep Med Rev. 2015;20:46-58.

Oliveira J, Etain B, Lajnef M, Hamdani N, Bennabi M, Bengoufa D, Sundaresh A Chaabane AB, Bellivier F, Henry C, Kahn JP, Charron D, Krishnamoorthy R, Leboyer M, Tamouza R. Combined effect of TLR2 gene polymorphism and early life stress on the age at onset of bipolar disorders. PLoS One. 2015;10:e0119702.

Parmentier C, Etain B, Yon L, Misson H, Mathieu F, Lajnef M, Cochet B, Raust A, Kahn JP, Wajsbrot-Elgrabli O, Cohen R, Henry C, Leboyer M, Bellivier F. Clinical and dimensional characteristics of euthymic bipolar patients with or without suicidal behavior. Eur. Psychiatry. 2012;27:570-6.

Post RM, Altshuler LL, Kupka R, McElroy SL, Frye MA, Rowe M, Leverich GS, Grunze H, Suppes T, Keck PE Jr, Nolen WA. Verbal abuse, like physical and sexual abuse, in childhood is associated with an earlier onset and more difficult course of bipolar disorder. Bipolar Disord. 2015;17:323-30.

Price LH, Kao HT, Burgers DE, Carpenter LL, Tyrka AR. Telomeres and early-life stress: an overview. Biol Psychiatry. 2013;73:15-23.

Read J, Fraser A. Staff response to abuse histories of psychiatric inpatients. Aust NZ J Psychiatry. 1998;32:206-13.

Roy CA, Perry JC. Instruments for the assessment of childhood trauma in adults. J Nerv Ment Dis. 2004;192:343-51. 
Russo M, Mahon K, Shanahan M, Solon C, Ramjas E, Turpin J, Burdick E. The association between childhood trauma and facial emotion recognition in adults with bipolar disorder. Psychiatry Res. 2015;229:771.

Savitz JB, van der Merwe L, Stein DJ, Solms M, Ramesar RS. Neuropsychological task performance in bipolar spectrum illness: genetics, alcohol abuse, medication and childhood trauma. Bipolar Disord. 2008;10:479-94.

Schafer V, Bader K. Relationship between early-life stress load and sleep in psychiatric outpatients: a sleep diary and actigraphy study. Stress Health. 2013;29:177-89.

Seckl JR, Meaney MJ. Glucocorticoid programming. Ann NY Acad Sci. 2004;1032:63-84.

Semiz UB, Inanc L, Bezgin CH. Are trauma and dissociation related to treatment resistance in patients with obsessive-compulsive disorder? Soc Psychiatry Psychiatr Epidemiol. 2014;49:1287-96.

Shalev I, Entringer S, Wadhwa PD, Wolkowitz OM, Puterman E, Lin J, Epel ES. Stress and telomere biology: a lifespan perspective. Psychoneuroendocrinology. 2013;38:1835-42.

Shamseddeen W, Asarnow JR, Clarke G, Vitiello B, Wagner KD, Birmaher B, Keller MB, Emslie G, Iyengar S, Ryan ND, McCracken JT, Porta G, Mayes T, Brent DA. Impact of physical and sexual abuse on treatment response in the Treatment of Resistant Depression in Adolescent Study (TORDIA). J Am Acad Child Adolesc Psychiatry. 2011;50:293-301.

Shevlin M, Dorahy MJ, Adamson G. Trauma and psychosis: an analysis of the National Comorbidity Survey. Am J Psychiatry. 2007;164:166-9.

Sugaya L, Hasin DS, Olfson M, Lin KH, Grant BF, Blanco C. Child physical abuse and adult mental health: a national study. J Trauma Stress. 2012;25:384-92.

Swendsen J, Hammen C, Heller T, Gitlin M. Correlates of stress reactivity in patients with bipolar disorder. Am J Psychiatry. 1995;152:795-7.

Thompson AD, Nelson B, Yuen HP, Lin A, Amminger GP, McGorry PD, Wood SJ, Yung AR. Sexual trauma increases the risk of developing psychosis in an ultra high-risk "prodromal" population. Schizophr Bull. 2014;40:697-706.
Tursich M, Neufeld RW, Frewen PA, Harricharan S, Kibler JL, Rhind SG, Lanius RA. Association of trauma exposure with proinflammatory activity: a transdiagnostic meta-analysis. Transl Psychiatry. 2014;4:e413.

Uher R. Gene-environment interactions in severe mental illness. Front Psychiatry. 2014;5:48.

van Harmelen AL, van Tol MJ, Demenescu LR, van der Wee NJ, Veltman DJ, Aleman A, van Buchem MA, Spinhoven P, Penninx BW, Elzinga BM. Enhanced amygdala reactivity to emotional faces in adults reporting childhood emotional maltreatment. Soc Cogn Affect Neurosci. 2013;8:362-9.

van Leeuwen AP, Creemers HE, Greaves-Lord K, Verhulst FC, Ormel J, Huizink AC. Hypothalamic-pituitary-adrenal axis reactivity to social stress and adolescent cannabis use: the TRAILS study. Addiction. 2011;106:1484-92.

Watson S, Gallagher P, Dougall D, Porter R, Moncrieff J, Ferrier IN, Young $\mathrm{AH}$. Childhood trauma in bipolar disorder. Aust NZ J Psychiatry. 2014:48:564-70.

Weber K, Rockstroh B, Borgelt J, Awiszus B, Popov T, Hoffmann K, Schonauer K, Watzl H, Propster K. Stress load during childhood affects psychopathology in psychiatric patients. BMC Psychiatry. 2008;8:63.

Wentzensen IM, Mirabello L, Pfeiffer RM, Savage SA. The association of telomere length and cancer: a meta-analysis. Cancer Epidemiol Biomarkers Prev. 2011;20:1238-50.

WHO Library Cataloguing-in-Publication Data. World Health Organization and International Society for Prevention of Child Abuse and Neglect. Preventing child maltreatment: a guide to taking action and generating evidence. In (Anonymous). 2006.

Willeit P, Raschenberger J, Heydon EE, Tsimikas S, Haun M, Mayr A, Weger S, Witztum JL, Butterworth AS, Willeit J, Kronenberg F, Kiechl S. Leucocyte telomere length and risk of type 2 diabetes mellitus: new prospective cohort study and literature-based meta-analysis. PLoS One. 2014;9:e112483.

\section{Submit your manuscript to a SpringerOpen ${ }^{\circ}$ journal and benefit from:}

- Convenient online submission

- Rigorous peer review

- Immediate publication on acceptance

- Open access: articles freely available online

- High visibility within the field

- Retaining the copyright to your article

Submit your next manuscript at $>$ springeropen.com 